\title{
Measuring 3-dimensional tooth movement with a 3-dimensional surface laser scanner
}

\author{
Badri Thiruvenkatachari, ${ }^{a}$ Mariam Al-Abdallah, ${ }^{a}$ Noreen C. Akram, ${ }^{b}$ Jonathan Sandler, ${ }^{c}$ and Kevin O'Brien ${ }^{d}$ \\ Manchester and Chesterfield, United Kingdom
}

Introduction: Our aims in this study were to (1) develop a method of measuring 3-dimensional (3D) tooth movement using a 3D surface laser scanner, (2) test the accuracy of this method, and (3) compare the measurements with those from cephalometric radiographs. Methods: A method of superimposing pretreatment and posttreatment models on the palatal rugae was developed, and an experimental model was prepared to evaluate the accuracy and reliability of the laser scanner. Records were obtained from a prospective longitudinal randomized clinical trial evaluating anchorage loss with headgears and midpalatal osseointegrated implants as a source of anchorage in Chesterfield, United Kingdom. The pretreatment and posttreatment study models were analyzed by using a 3D laser scanner to measure the 3D tooth movement. Results: The laser scanner was accurate to $0.0235 \mathrm{~mm}$ for anteroposterior measurements and $0.0071 \mathrm{~mm}$ for buccolingual movements for every $0.5 \mathrm{~mm}$ of movement. The study model analysis showed that mesial molar movements were $1.38 \mathrm{~mm}$ on the right side and $1.11 \mathrm{~mm}$ on the left side for the implant group, and $2.24 \mathrm{~mm}$ on right side and $1.63 \mathrm{~mm}$ on left side for the headgear group, with no statistically significant difference between the groups. The results for vertical movement of molars showed extrusion on both sides in both groups but no statistically significant difference between the groups. In the transverse plane, the results were not statistically significantly different between the groups. The results from superimposition of lateral cephalograms were similar to those obtained from the scanner. Conclusions: The 3D laser scanner provides accurate and reliable measurements of tooth displacement and can be considered an alternative to cephalometric radiographs. (Am J Orthod Dentofacial Orthop 2009;135:480-5)

I

$\mathrm{n}$ this article, we outline a new methodology of evaluating 3-dimensional (3D) tooth movement from study models using 3D surface laser scanning. Over many years, orthodontic research has been confined to measuring tooth movement in 2 dimensions with radiographs and study models. Attempts have been made to solve this problem with 3D cephalometric radiographs, ${ }^{1}$ $3 \mathrm{D}$ occlusograms, ${ }^{2}$ automated infrared photogrammetry, ${ }^{3}$ holographic projections, ${ }^{4}$ stereolithographs, ${ }^{5}$ and virtual reality ${ }^{6}$; but none of these novel methods has been widely used. A later development is the 3D laser scanner, first introduced for facial measurement ${ }^{7}$ and den-

\footnotetext{
${ }^{a}$ Research student, School of Dentistry, University of Manchester, Manchester, United Kingdom.

${ }^{\mathrm{b}}$ Specialist registrar, School of Dentistry, University of Manchester, Manchester, United Kingdom.

${ }^{\mathrm{c}}$ Consultant orthodontist, Chesterfield Royal NHS Trust, Chesterfield, United Kingdom.

${ }^{\mathrm{d}}$ Professor of orthodontics, School of Dentistry, University of Manchester, Manchester, United Kingdom.

The authors report no commercial, proprietary, or financial interest in the products or companies described in this article.

Reprint requests to: Badri Thiruvenkatachari, Orthodontic Research Unit, 3rd Floor, Coupland III Building, School of Dentistry, University of Manchester, Manchester-M15 6FH, United Kingdom; e-mail, badri_chari@yahoo.com. Submitted, January 2007; revised and accepted, March 2007. $0889-5406 / \$ 36.00$

Copyright (C) 2009 by the American Association of Orthodontists. doi:10.1016/j.ajodo.2007.03.040
}

tal model analysis. ${ }^{8}$ Recent developments have been high-powered 3D systems that can capture the shape and color of an object in only 2.5 seconds and acquire a highly detailed rich 24-bit color resolution. To date, this method has not been used for study cast analysis.

Our aims in this study were to (1) develop a method of measuring 3D tooth movement using a 3D surface laser scanner, (2) test the accuracy of this method, and (3) compare the measurements with those derived from cephalometric radiographs.

\section{MATERIAL AND METHODS}

The system that we used was comprised of a 3D surface laser scanner (VIVID 910i, Konica Minolta Sensing, Tokyo, Japan), a tripod, a rotating stage, an exchangeable lens, a personal computer, and Rapidform 2006 software (INUS Technology and Rapidform Inc, Seoul, Korea). The newly developed system uses new hardware design and improved measurement algorithms to provide 4 times the measurement accuracy of previous models. ${ }^{9}$ This scanner is based on the principle of laser triangulation. A target (model) is scanned with laser stripes, and the charged-couple device camera receives the light reflected from the surface of the model. Surface shape measurements of the model are 


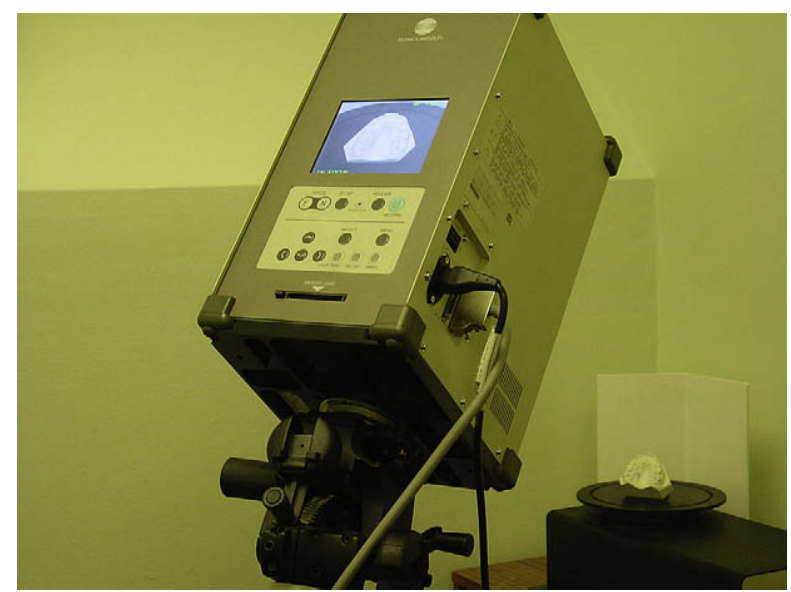

Fig 1. 3D laser scanner and the model on the rotating stage.

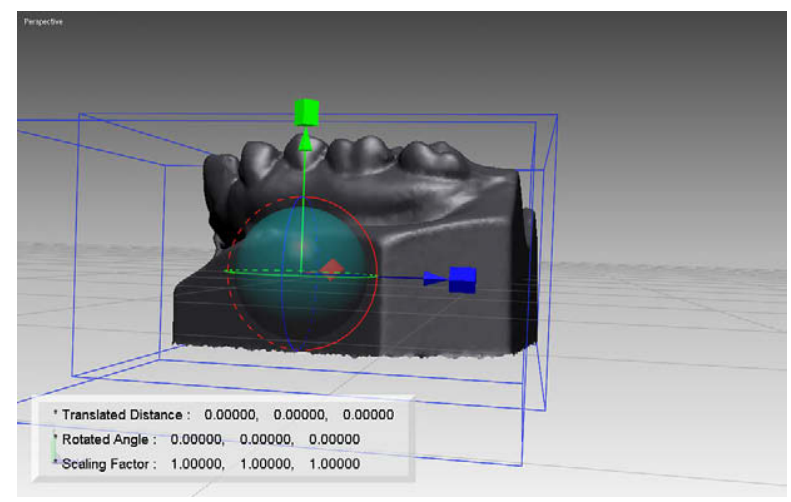

Fig 2. Aligning the models with the shell tracker ball.

recorded through triangulation and converted into a $3 \mathrm{D}$ polygon mesh. The scanner measures $640 \times 480$ points with 1 scan, simultaneously acquiring both surfaceshape and color-image data.

The scanning and measurement procedure that we developed was as follows. The study models were placed on the rotating stage set at an angle of $45^{\circ}$ to the horizontal so that the laser beam hits the horizontal part of the hard palate at right angles (Fig 1). The model was then scanned and the surface converted to a lattice of 300,000 connected points. The 3D image was captured by a computer and then viewed and manipulated by using the Rapidform 2006 software.

The pretreatment and posttreatment models were then superimposed on the palatal rugae by using the following steps.

1. The scanned pretreatment and posttreatment models were first aligned on the same plane by us-

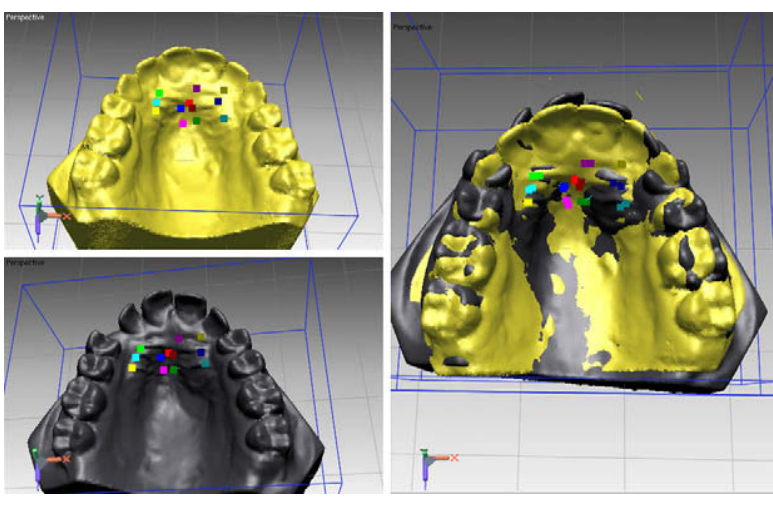

Fig 3. Initial registration by selecting 12 stable points on the palate.

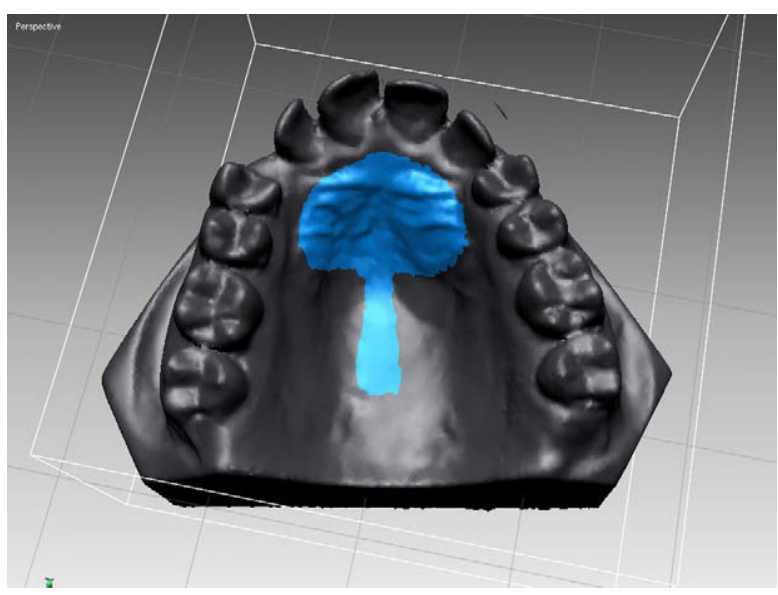

Fig 4. Regional registration by selecting a mushroomshaped area on the palate.

ing the shell tracker ball (Fig 2). The occlusal plane was taken as the reference for aligning the models so that both models were aligned with the occlusal plane parallel to the horizontal. The model was rotated in all planes to confirm that the occlusal plane was horizontal.

2. The models were then superimposed on the palatal anatomy. The first stage was done by selecting the medial and lateral end points of prominent rugae on each side of the palate (Fig 3). The scans of the models were superimposed with the software, and a preliminary check of the quality of the superimposition was made. Then a mushroom-shaped region of the palate (Fig 4) on both models was selected, and these 2 areas were registered on each other. Superimposition was done in 2 stages to obtain accurate results. 


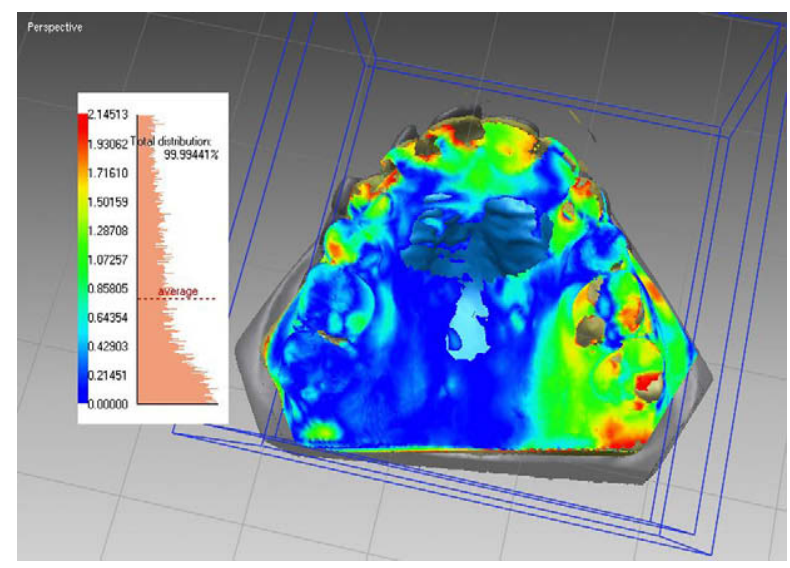

Fig 5. The difference in registration between the pretreatment and posttreatment models.
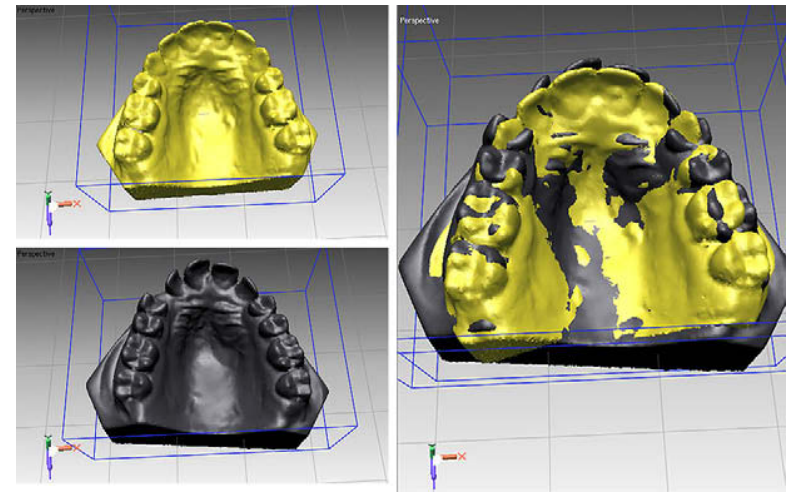

Fig 6. Superimposed pretreatment and posttreatment models.

3. After superimposing, the difference between the pretreatment and posttreatment models (shellto-shell deviation) was evaluated. This difference was visualized by using a color-coding system (Fig 5), with blue denoting no differences and red denoting a difference greater than $0.8 \mathrm{~mm}$. A difference less than $0.8 \mathrm{~mm}$ was acceptable. If the difference was greater than $0.8 \mathrm{~mm}$, the entire procedure was repeated from the start-ie, from alignment of the models. The procedure was repeated until a difference of less than $0.8 \mathrm{~mm}$ was obtained between models. The error of 0.799 was for the entire process of point identification, computer modeling, and superimposition. An example of pretreatment, posttreatment, and superimposed models is shown in Figure 6. The cross-sectional views of the models give a precise representation of the superimposition (Figs 7 and 8).

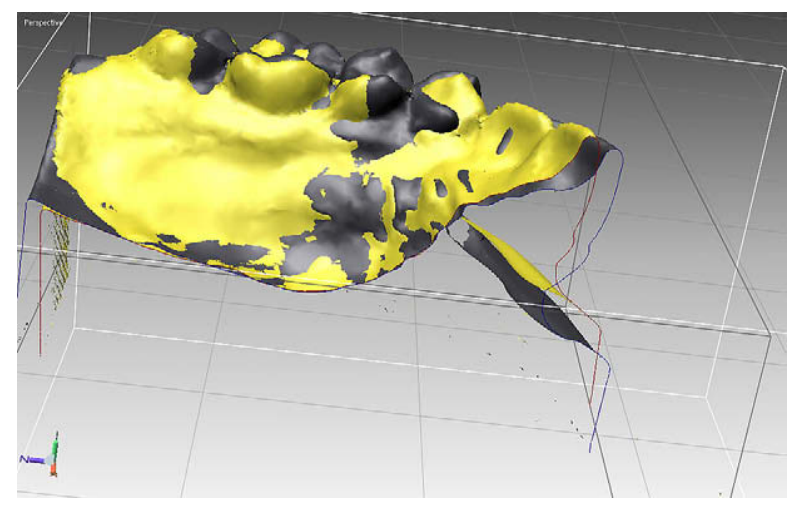

Fig 7. Cross-sectional view of the superimposed model in the sagittal plane.

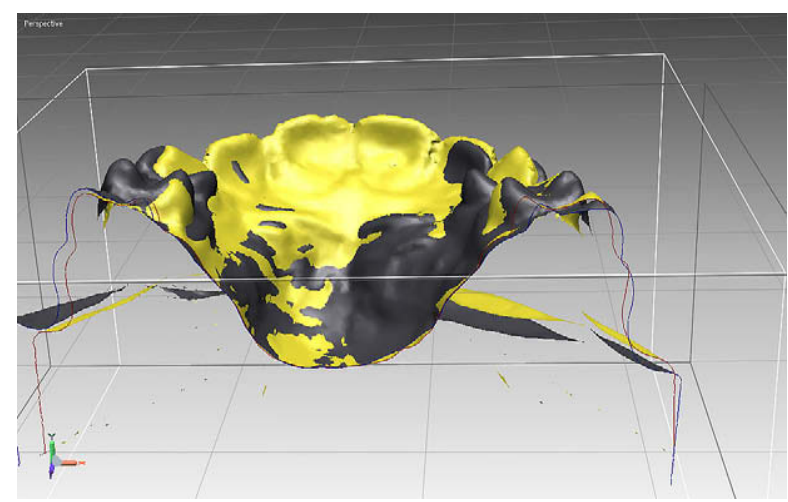

Fig 8. Cross-sectional view of the superimposed model in the transverse plane.

4. The next step was to identify the center of mass of the pretreatment and posttreatment molars. The clinical crown of the molar was traced, and the software calculated the center of mass of the tooth (Fig 9). This procedure was performed for both sides and for the pretreatment and posttreatment models, thus allowing calculation of molar movement in all 3 planes of space (Fig 10). The total procedure took about 30 minutes for each set of models.

The accuracy of the scanner and the Rapidform software was analyzed by using 2 methods. The first method was to measure the intermolar arch widths of 50 patients' study models with a digital caliper and the laser scanner, and compare them. The second method was by using an experimental model. We prepared an experimental model by fixing a maxillary study cast to a metal plate (Fig 11) and suspended a molar from a small jig attached to the metal plate. This allowed the molars to be moved by a distance that could be accurately 


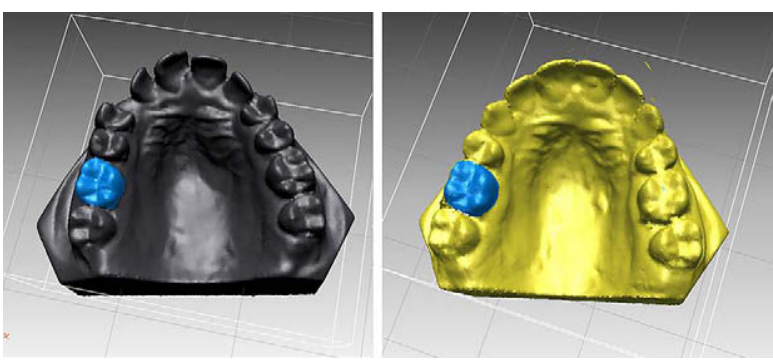

Fig 9. Identifying the center of mass of the first molar.

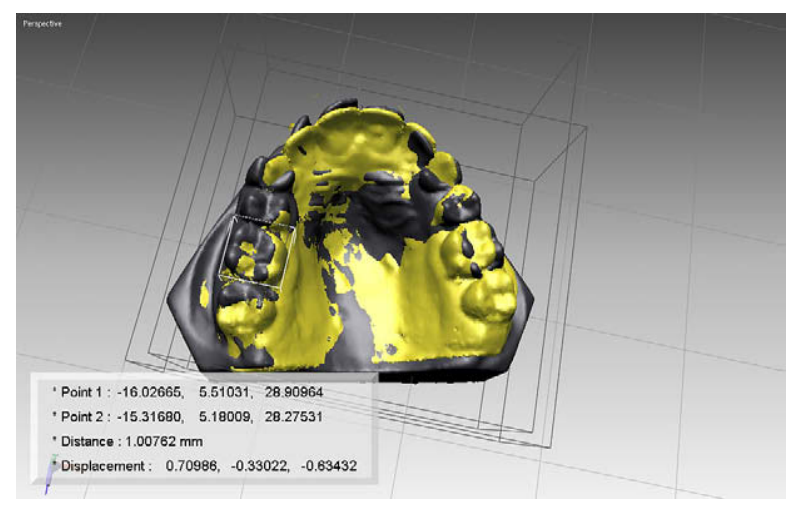

Fig 10. Difference between pretreatment and posttreatment molar movement on the right side in all 3 planes.

measured with the digital vernier calipers. We then moved the tooth mesiodistally and buccopalatally in $0.5-\mathrm{mm}$ increments and scanned the cast after each movement. This movement was analyzed with the method outlined above.

The final stage of our study was to compare the values from a previous cephalometric study of molar movement with measurements made with the laser scanner. We obtained study casts from a randomized controlled trial that evaluated molar movement when anchorage was reinforced with either headgear or midpalatal osseointegrated implants. Details of this study and the molar movement from cephalometric radiographs were previously published. ${ }^{10}$ The study casts were scanned and measured, as outlined above.

\section{RESULTS}

The measurement of intermolar arch width by caliper and laser scanner showed a difference of $0.06 \mathrm{~mm}$ that was not statistically significant $(P>0.05)$ (Table I).

In the experimental model, the average movement of the molars, measured by laser scanner, in the anteroposterior plane was $0.523 \mathrm{~mm}$, and the average movement in the buccopalatal plane was $0.507 \mathrm{~mm}$ for
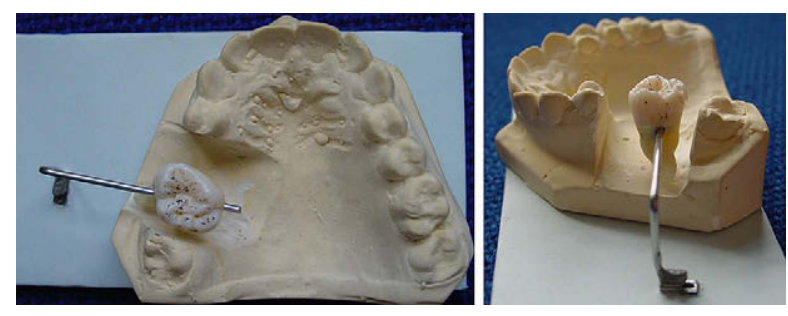

Fig 11. Experimental model: occlusal and side views with the mobile molar unit.

every $0.5 \mathrm{~mm}$ of molar movement measured by digital caliper. This showed that the scanner was accurate to $0.023 \mathrm{~mm}$ for anteroposterior movements and to 0.007 $\mathrm{mm}$ for buccopalatal movements.

We scanned the models from 22 patients in the headgear group and 20 patients in the implant group and then analyzed 3D molar tooth movement. The results are shown in Table II. There were no statistically significant differences in tooth movement between the groups. These values and conclusions are similar to those obtained from superimposing pretreatment and posttreatment lateral cephalometric radiographs, which showed molar anchorage loss (sagittal plane) of $3 \mathrm{~mm}$ for the headgear group and $1.5 \mathrm{~mm}$ for the implant group. ${ }^{10}$

\section{DISCUSSION}

This study showed that 3D laser scanning and this method of analyzing tooth movement is sufficiently accurate for orthodontic investigations and is an alternative to cephalometric analysis for tooth movement. Furthermore, 3D laser scanning has some advantages over cephalometric measurement. There is no need to expose the patient to ionizing radiation, and it is possible to measure tooth movement of individual teeth in all 3 planes of space with great accuracy.

This method and software appear to be an improvement on previous studies that used laser scanning. For example, Kuroda et al $^{11}$ used slit-ray laser projectors and 2 charged-couple device cameras to capture imaged of the study models. They concluded that, although the scans were accurate, unfortunately they could not scan the undercuts; this compromised their results. In a similar investigation, 3D distal movement of molars was analyzed and compared with radiographic measurement. ${ }^{12}$ The authors concluded that laser scanner measurement had significantly fewer errors than radiographic measurement. However, they did not publish the accuracy study of the scanner.

More recently, Sohmura et al ${ }^{13}$ used a 3D laser scanner (VIVID 700, Minolta, Osaka, Japan) for dental model analysis. They found the system to be accurate 
Table I. Evaluation of the accuracy of the laser scanner by comparing measurements from the digital caliper and the laser scanner

\begin{tabular}{|c|c|c|c|c|c|c|c|}
\hline & \multirow[b]{2}{*}{$n$} & \multicolumn{3}{|c|}{ Mean (mm) } & \multirow[b]{2}{*}{ міпітит } & \multirow[b]{2}{*}{ Махітит } & \multirow[b]{2}{*}{$S D$} \\
\hline & & $\begin{array}{c}\text { Manual } \\
\text { (digital caliper) }\end{array}$ & $\begin{array}{l}\text { Laser } \\
\text { scanner }\end{array}$ & Difference & & & \\
\hline $\begin{array}{l}\text { Anteroposterior movement on } \\
\text { experimental model }\end{array}$ & 10 & 0.5 & 0.5235 & 0.0235 & 0.46 & 0.62 & 0.05253 \\
\hline $\begin{array}{l}\text { Buccolingual movement on } \\
\text { experimental model }\end{array}$ & 10 & 0.5 & 0.5071 & 0.0071 & 0.47 & 0.56 & 0.03428 \\
\hline $\begin{array}{l}\text { Intermolar arch width on } \\
\text { patients' study models }\end{array}$ & 50 & 47.77 & 47.83 & 0.06 & $\begin{array}{c}-0.91 \\
\text { (difference) }\end{array}$ & $\begin{array}{c}0.99 \\
\text { (difference) }\end{array}$ & $\begin{array}{c}0.39 \\
\text { (difference) }\end{array}$ \\
\hline
\end{tabular}

Table II. Mean values (mm) of 3D molar movement for the implant and headgear groups

\begin{tabular}{|c|c|c|c|}
\hline & \multicolumn{2}{|c|}{ Mean $(S D)$} & \multirow[b]{2}{*}{$\mathrm{P}$ value } \\
\hline & Headgear group & Implant group & \\
\hline Mesial molar movement on right side & $2.2386(2.0463)^{*}$ & $1.3771(2.8795)^{*}$ & 0.268 \\
\hline Mesial molar movement on left side & $1.6343(2.2866)^{*}$ & $1.1120(2.6269)^{*}$ & 0.495 \\
\hline Vertical molar movement on right side & $0.5545(0.7432)^{\dagger}$ & $0.0805(1.1967)^{\dagger}$ & 0.128 \\
\hline Vertical molar movement on left side & $0.4505(0.7147)^{\dagger}$ & $0.2150(0.6216)^{\dagger}$ & 0.264 \\
\hline Transverse molar movement on right side & $0.3301(0.6860)^{\ddagger}$ & $0.5570(0.9320)^{\ddagger}$ & 0.372 \\
\hline Transverse molar movement on left side & $0.3710(0.8210)^{\S}$ & $0.0920(0.7848)^{\ddagger}$ & 0.070 \\
\hline
\end{tabular}

*Mesial movement; ${ }^{\dagger}$ extrusive movement; ${ }^{\star}$ buccal movement; ${ }^{\S}$ palatal movement.

to evaluate tooth measurements. This system, however, was at the developmental stage, and the study models had to be placed in 4 directions to compensate for the undercuts and to acquire the attempted shape. The system that we described scans the model in 1 shot, including the undercut areas.

Kusnoto and Evans ${ }^{14}$ tested the accuracy of the VIVID 700 laser scanner and showed it to be accurate with an error range between 0.2 and $0.7 \mathrm{~mm}$. Unfortunately, they found that the $\mathrm{z}$ coordinates were enlarged and had to introduce a correction factor to compensate for the error. They also had problems with the undercuts and scanned the models at 3 angulations $\left(-45^{\circ}, 0^{\circ}\right.$, and $\left.45^{\circ}\right)$. Our system was corrected for accuracy in all 3 planes.

Ashmore et $\mathrm{al}^{15}$ used a $3 \mathrm{D}$ digitizer that collected 3D data with a stylus tip for analyzing the models from a previous randomized clinical trial. They did an error calculation but not an accuracy test for the digitizer measurements.

The major advantages of using laser scanners are high speed, accuracy, and reproducibility. This study adds to other investigations that showed that these devices are extremely accurate for dental cast analysis. Furthermore, their use will reduce the need for storage of plaster models and might be more cost effective when the cost of storage space is considered.

The disadvantages of this technique include the time (30 minutes) required to complete the 3D scanning and analysis of dental casts, and the initial purchase costs of the scanner and software $(\$ 40,000)$. In addition, analyzing the casts requires special training to establish accuracy. Time and cost are, however, likely to be reduced in the future as new hardware systems and new software become available.

\section{CONCLUSIONS}

The 3D laser scanner provides accurate and reliable measurements of tooth displacement and might be an alternative to cephalometric radiographs.

We thank Brian Daber and David Watts for their help with the experimental model.

\section{REFERENCES}

1. Grayson B, Cutting C, Bookstein FL, Kim H, McCarthy JG. The three-dimensional cephalogram: theory, technique, and clinical application. Am J Orthod Dentofacial Orthop 1988;94: 327-37.

2. Fiorelli G, Melsen B. The "3-D occlusogram" software. Am J Orthod Dentofacial Orthop 1999;116:363-8.

3. Ferrario VF, Sforza C, Serrao G, Miani A Jr. A computerized noninvasive method for the assessment of human facial volume. J Craniomaxillofac Surg 1995;23:280-6.

4. Burstone CJ, Every TW, Pryputniewicz RJ. Holographic measurement of incisor extrusion. Am J Orthod 1982;82:1-9.

5. Kermer C, Rasse M, Lagogiannis G, Undt G, Wagner A, Millesi W. Colour stereolithography for planning complex 
maxillofacial tumour surgery. J Craniomaxillofac Surg 1998;26: 360-2.

6. Kordass B, Gartner C, Sohnel A, Bisler A, Voss G, Bockholt U, et al. The virtual articulator in dentistry: concept and development. Dent Clin North Am 2002;46:493-506.

7. Moss JP, Linney AD, James DR. Three dimensional digitization of the face and skull. J Maxillofac Surg 1985;13:136-43.

8. Soma K, Hisano M, Kuroki T, Ishida T, Kuroda T. High accuracy measuring device for dental cast—using device with flat laser beam. Kokubyo Gakkai Zasshi 1992;59:259-64.

9. Press release: Konica Minolta Sensing. Konica Minolta, Tokyo, Japan. Available at: http://www.konicaminolta-3d.com/index. php?id=13. Accessed on January 20, 2007.

10. Benson PE, Tinsley D, O’Dwyer JJ, Majumdar A, Doyle P, Sandler PJ. Midpalatal implants for orthodontic anchoragea randomized clinical trial. Am J Orthod Dentofacial Orthop 2007;132:606-15.
11. Kuroda T, Motohashi N, Tominaga R, Iwata K. Three-dimensional dental cast analyzing system using laser scanning. Am J Orthod Dentofacial Orthop 1996;110:365-9.

12. Mavropoulos A, Karamouzos A, Kiliaridis S, Papadopoulos MA. Efficiency of noncompliance simultaneous first and second upper molar distalization: a three-dimensional tooth movement analysis. Angle Orthod 2005;75:468-75.

13. Sohmura T, Kojima T, Wakabayashi K, Takahashi J. Use of an ultra high-speed laser scanner for constructing three-dimensional shapes of dentition and occlusion. J Prosthet Dent 2000;84:345-52.

14. Kusnoto B, Evans CA. Reliability of a 3D surface laser scanner for orthodontic applications. Am J Orthod Dentofacial Orthop 2002;122:342-8.

15. Ashmore JL, Kurland BF, King GJ, Wheeler TT, Ghafari J, Ramsay DS. A three-dimensional analysis of molar movement during headgear treatment. Am J Orthod Dentofacial Orthop 2002;121:18-30. 